\title{
MODELOS DE DETERMINAÇÃO NÃO DESTRUTIVO DA ÁREA FOLIAR DO FEIJOEIRO COMUM (Phaseolus vulgaris L.)
}

FIGUEIREDO, Edipo da Silva ${ }^{1}$

SANTOS, Mateus Eduardo dos ${ }^{1}$

GARCIA, Anice ${ }^{2}$

\begin{abstract}
RESUMO: O experimento foi instalado e conduzido de junho a agosto em casa de vegetação, pertencente à "Faculdade Dr. Francisco Maeda" - FAFRAM, com o objetivo de determinar uma equação que permita estimar a área foliar do feijoeiro cv. Perola comum a partir de medidas de dimensões foliares. As medidas foram realizadas em folíolos coletados de plantas cultivadas em vasos. A área foliar real foi determinada utilizando um planímetro, marca Koizumi - modelo KP - 27, sendo determinada a área das fotocópias dos folíolos. Foram avaliados oito modelos teóricos, com equações dos tipos potencial e linear (interceptando a origem), quanto à precisão para estimar a área foliar a partir das medidas de largura e/ou comprimento de cada folíolo. Através dos resultados obtidos constata-se que existe alta correlação entre os dados medidos e estimados da área foliar do feijão.As medidas de comprimento e largura das folhas são adequados para estimar a área foliar da feijão cv Pérola de forma rápida e sem a necessidades de coletar a folha, sendo que a regressão do tipo potencial apresenta melhor ajuste para todos os modelos testados, com exceção do produto de comprimento pela largura em que o ajuste linear também apresentação excelente correlação.
\end{abstract}

Palavras-chave: Regressão linear. Regressão potencial. Cultivar perola. Análise de crescimento.

SUMMARY: The experiment was conduted to evaluate a mathematical model for measuring the leaf area of common bean cv. Perola using the parameters length and width. The measures of leaf area performed in collected leaflets of plants cultivated in vases. The real leaf area was determine using a planimeter, Koizumi brand model - KP - 27 and determined the area of photocopies of leaflets. Was evaluate eight theoretical models, with equations of potential and linear types (intercepting the origin), as to the accuracy to estimate leaf area from measurements of width and / or length of each leaflet. From the results it appears that there is high correlation between the measured and estimated leaf area. As the length and width of the leaves are suitable for estimating the leaf area of bean cv Perola quickly and without the need for collect leaf. The equations of potential type has a better fit for all models except the product of length by width in which the linear fit also show excellent correlation.

Keywords: Linear regression. Potential regression. Cultivar perola. Growth analysis.

\section{INTRODUÇÃO}

O feijão (Phaseolus vulgaris L.) é a leguminosa mais importante para o consumo humano, principalmente nos países em desenvolvimento (FAGERIA; BARBOSA FILHO; STONE, 2004), possuindo, segundo Vilhordo et al. (1980) os seguintes hábitos de crescimento, Tipo I - determinado arbustivo, com ramificação ereta e fechada; Tipo II - indeterminado, com ramificação ereta e fechada; Tipo III - indeterminado, com ramificação aberta e Tipo IV - indeterminado, prostrado ou trepador.

A análise de crescimento é uma ferramenta para melhor conhecimento da planta como entidade biológica e que permite manejar, racionalmente, as espécies cultivadas para expressão do seu potencial de produção. Também permite avaliar o crescimento da planta como um todo e a contribuição dos diferentes

\footnotetext{
${ }^{1}$ Engenheiro Agrônomo FE/FAFRAM

${ }^{2}$ Dra. em Ciência do Solo. Docente da FE/FAFRAM - e-mail: anice@ feituverava.com.br
} 
órgãos para o crescimento total. A partir dos dados de crescimento, pode-se inferir sobre a atividade fisiológica, isto é, estimar as causas de variações de crescimento entre plantas geneticamente diferentes, ou entre plantas semelhantes crescendo em ambientes diferentes (BENINCASA, 2003). Brandes et al. (1971), afirmam que o rendimento do feijoeiro depende do índice de área foliar no florescimento, sendo que maior crescimento dos ramos resultará em aumento da área foliar, maior interceptação de luz e consequentemente maior produtividade de grãos. Pereira et al (2012) avaliando as características morfoagronômicas do milho sob efeito de diferentes níveis de desfolha em três fases fenológicas, observaram a relação negativa da diminuição da área foliar e produtividade de milho, devido a diminuição da relação fonte-dreno.

A determinação da área foliar de plantas é, portanto, uma importante ação que permite ao pesquisador obter indicativo de resposta de tratamentos aplicados e lidar com uma variável que se relacione diretamente com a capacidade fotossintética e de interceptação da luz (SEVERINO et al., 2004).

A determinação da área foliar pode ser realizada por métodos diretos ou indiretos e destrutivos ou não destrutivos. Os métodos diretos utilizam medidas realizadas diretamente nas folhas. Os métodos destrutivos exigem a retirada da folha ou outras estruturas, o que muitas vezes não e possível devido a limitação do numero de plantas na parcela experimental. Nos métodos não destrutivos as medidas são tomadas na planta, sem necessidade de remoção de estruturas, preservando sua integridade e permitindo acompanhar o crescimento e a expansão foliar da mesma planta até o final do ciclo ou do experimento. Além disso, segundo Silva et al. (1998) o método não destrutivo reduz o erro experimental associado com procedimentos de amostragens destrutivas, tornando importante para avaliar o crescimento das plantas nas condições de campo a busca de métodos fáceis de serem executados, rápidos e não-destrutivos que estimem a área foliar com precisão.

Funções de regressão são equações que demonstram a relação existente entre dois conjuntos de valores, isto é, através de uma base de dados, procuram estimar valores de uma variável Y, correspondente ao valor conhecido de uma variável X. O grau de relação entre as variáveis é chamado correlação, e é representado por um coeficiente que varia de -1 a 1 . Se todos os valores das variáveis satisfazem exatamente uma equação, diz-se que elas estão perfeitamente correlacionadas (SPIEGEL, 1994).

O objetivo deste trabalho foi determinar uma equação que permita estimar a área foliar do feijoeiro comum a partir de medidas de dimensões de comprimento e largura dos folíolos.

\section{MATERIAL E MÉTODOS}

O experimento foi instalado e conduzido de junho a agosto em casa de vegetação, pertencente à "Faculdade Dr. Francisco Maeda" - FAFRAM, no município de Ituverava/SP, situada nas coordenadas $20^{\circ} 20^{\prime} \mathrm{S}, 47^{\circ} 46^{\prime} \mathrm{W}$ e 605 metros de altitude.

O tipo climático para Ituverava/SP foi definido como tipo Aw - megatérmico (tropical úmido) com temperatura média do mês mais frio acima de $18^{\circ} \mathrm{C}$, denominado clima de savanas, com inverno seco e chuvas máximas de verão. A média anual de precipitação é de $1518 \mathrm{~mm}$ com temperatura média anual de $23,3^{\circ} \mathrm{C}$., o período mais seco do ano estende-se entre abril e outubro, com a máxima deficiência hídrica sendo atingida no final do mês de agosto, observa-se que o excedente hídrico ocorre nos meses de novembro a março. (CARRER; GARCIA, 2007).

A cultura estudada foi a do feijoeiro comum (Phaseolus vulgaris L.), tipo carioca, cultivar Pérola, pertencente ao hábito de crescimento tipo III (indeterminado, com ramificação aberta), desenvolvido pela EMBRAPA, que apresenta as seguintes características: ciclo normal (85 a 95 dias); massa média de 100

Nucleus, v.9, n.1, abr.2012 
grãos igual a 27 gramas; arquitetura semi-ereta; potencial produtivo de $3.903 \mathrm{~kg} \mathrm{ha}^{-1}$; não adaptado a colheita mecânica direta; sendo suscetível à antracnose, ao crestamento bacteriano, à ferrugem e ao mosaico dourado; intermediário à mancha angular e ao fusarium e resistente ao mosaico comum. O cultivar Pérola é indicado para a terceira safra nos estados de Espírito Santo, São Paulo, Goiás, Distrito Federal, Minas Gerais, Mato Grosso e Tocantins (EMBRAPA, 2010).

A semeadura e a adubação foram realizadas manualmente no dia 02/06/2010 sendo semeadas 5 sementes por vaso, e após a emergência foi realizado o desbaste deixando apenas uma planta por vaso.

A coleta de plantas foram realizadas no estádios fenológico R8 (desenvolvimento das sementes). Com o auxílio de uma tesoura (método destrutivo) os folíolos simétricos e assimétricos foram separados para que houvesse a medição individual. As folhas fotossinteticamente ativas e não danificadas foram separadas das demais partes da planta na inserção entre o limbo e o pecíolo. Em cada folha, mediram-se comprimento (C) ao longo da nervura central, considerando-se a distância desde o ápice da folha até a inserção do limbo com o pecíolo, e a maior largura (L) perpendicular ao alinhamento da nervura central, ambos em cm, utilizando-se uma régua graduada em milímetros.

Posteriormente, foram realizadas fotocópias das folhas impressas sobre papel xerográfico (sulfite $75 \mathrm{~g} / \mathrm{m} 2$ ), as quais foram utilizadas para a determinação da área real, utilizando um planímetro, marca Koizumi - modelo KP - 27, sendo determinada a área das fotocópias dos folíolos. Então a área real dos folíolos foi comparada com a área calculada dos mesmos, produto do comprimento (do ponto de inserção do pecíolo na lâmina até o ápice da folha), e da largura (maior largura do limbo foliar).

Foram avaliados oito modelos teóricos, com equações dos tipos potencial e linear (interceptando a origem), quanto à precisão para estimar a área foliar a partir das medidas de largura e/ou comprimento de cada folíolo. Nos modelos, a variável dependente (Y) foi representada pela área foliar real, medida pelo planímetro, e, como variável independente (X), foram consideradas a Largura (L) ou o Comprimento (C) ou o produto da largura pelo comprimento $(\mathrm{CxL})$ ou a soma de ambos $(\mathrm{C}+\mathrm{L})($ Tabela 1$)$.

Tabela 1. Modelos de equações para estimativa da área foliar do feijão cultivar Perola

\begin{tabular}{|c|c|c|}
\hline Modelos & Potencial & Linear \\
\hline Largura $(\mathrm{L})$ & $\mathrm{AF}=\Sigma\left(\mathrm{a} . \mathrm{L}^{\mathrm{b}}\right)$ & $\mathrm{AF}=\Sigma($ a. L) \\
\hline Comprimento (C) & $\mathrm{AF}=\Sigma\left(\mathrm{a} \mathrm{C}^{\mathrm{b}}\right)$ & $\mathrm{AF}=\Sigma(\mathrm{a} . \mathrm{C})$ \\
\hline Produto (L.C) & $\mathrm{AF}=\Sigma\left(\mathrm{a}(\mathrm{C} . \mathrm{L})^{\mathrm{b}}\right)$ & $\mathrm{AF}=\Sigma($ a. $(\mathrm{C} . \mathrm{L}))$ \\
\hline Soma $(\mathrm{L}+\mathrm{C})$ & $\mathrm{AF}=\Sigma\left(\mathrm{a}(\mathrm{C}+\mathrm{L})^{\mathrm{b}}\right)$ & $\mathrm{AF}=\Sigma(\mathrm{a} .(\mathrm{C}+\mathrm{L}))$ \\
\hline
\end{tabular}

$\mathrm{L}$ - Largura, $\mathrm{C}$ - Comprimento, AF - Área foliar, a e b - são parâmetros a serem estimados.

\section{RESULTADOS E DISCUSSÃO}

A Figura 1 possibilita a visualização das correlações dos Modelos de equações para estimativa da área foliar do feijão cultivar Perola. 
Figura 01 Equações de regressão para estimativa da área foliar e a relação entre a área foliar observa e a estimada obtida por diferentes modelos, utilizando a largura (1A, 1B) e comprimento (1C, 1D,), o produto do comprimento pela largura $(1 \mathrm{E} ; 1 \mathrm{~F})$ e a soma do comprimento pela largura $(1 \mathrm{Ge} 1 \mathrm{H})$ de folíolos de.feijão cultivar Perola. Ituverava, SP, 2010.

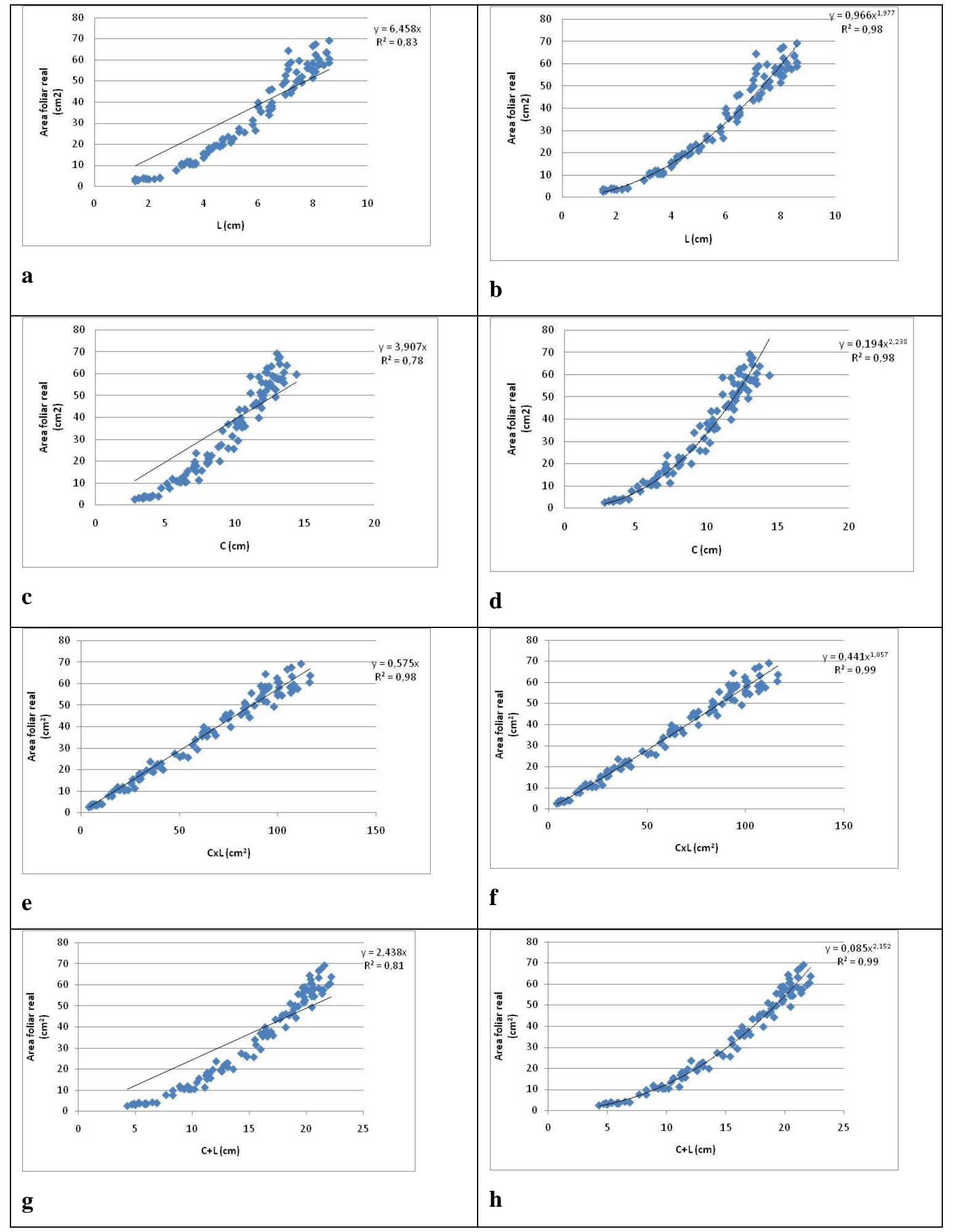

Analisando o comportamento dos modelos propostos, pode-se observar que todos apresentaram altos coeficientes de correlação para a determinação de área foliar. Nos modelos em que se utilizou somente a medida de comprimento ou largura (1A, 1B, 1C e 1D), ou a soma de ambos $(1 \mathrm{G}$ e $1 \mathrm{H})$ as equações do tipo potencial originaram uma correlação melhor do que as equações do tipo linear. 
Para o modelo em que se utilizou o produto do comprimento pela largura dos folíolos (1E e 1F), a regressão do tipo linear também apresentou uma excelente correlação, sendo que a área foliar pode ser estimada pela equação $\mathrm{AF}=\Sigma(0,575 .(\mathrm{CxL}))$. Resultados similares foram obtidos por Lima et al. (2008) para feijão caupi.

Para todos os modelos do tipo potencial, percebe-se que houve adequado ajuste entre os dados os quais originaram uma equação com coeficiente de determinação (R2) de $0,98(0,99)$ indicando que $98 \%$ (99\%) da variação total da área foliar foi explicada pela sua relação com a variável independente testada, sugerindo que é possível estimar a área foliar dos folíolos simétricos com ótima precisão, através do uso da equação gerada nos modelos.

\section{CONCLUSÃO}

Através dos resultados obtidos constata-se que existe alta correlação entre os dados medidos e estimados da área foliar do feijão.

As medidas de comprimento e largura das folhas são adequados para estimar a área foliar da feijão cv Pérola de forma rápida e sem a necessidades de coletar a folha, sendo que a regressão do tipo potencial apresenta melhor ajuste para todos os modelos testados, com exceção do produto de comprimento pela largura em que o ajuste linear também apresentação excelente correlação.

\section{REFERÊNCIAS}

BENINCASA, M. M. P.. Análise de crescimento de plantas: noções básicas. 2. ed. Jaboticabal: Funep, 2003.

BRANDES, D. et al. Efeitos da população de plantas e da epoca de plantio no crescimento do feijoeiro (Phaseolus vulgaris L.) II. Analise de crescimento. Experientiae, Viçosa, v. 15, n. , p.3-21, 1971.

CARRER, T.; GARCIA, A. Classificação climática para a cidade de Ituverava/SP. Nucleus, Ituverava, v.4, n.1, p. 29-37, 2007. Disponível em:

http://www.nucleus.feituverava.com.br/index.php/nucleus/article/view/9/36 Acesso em: 12 out. 2010.

EMBRAPA. Cultivares de feijão. Disponível em:

<http://www.cnpaf.embrapa.br/feijao/portifolio_feijao.pdf>. Acesso em: 12 out. 2010.

FAGERIA, N. K.; BARBOSA FILHO, M. P.; STONE, L. F.. Nutrição de Fósforo na Produção de Feijoeiro. In: YAMADA, Tsuioshi; ABDALLA, Silvia Regina Stipp e (Comp.). Fósforo na Agricultura

Brasileira. Piracicaba: Potafos, 2004. p. 435-455.

LIMA, C. J. G. S. et al. Modelos matemáticos para estimativa de área foliar de feijão caupí. Revista Caatinga, Mossoró, v. 21, n. 1, p. 120-127, 2008.

PEREIRA, M.J.R.et al. Características morfoagronômicas do milho submetido a diferentes níveis de desfolha manual. Revista Ceres. v. 59, n.2, p. 151-153, mar./abr., 2012 
SEVERINO, L. S.et al. Método para determinação da área foliar da mamoneira. Revista Brasileira de Oleaginosas e Fibrosas, v. 8, n. 1, p.753-762, 2004.

SILVA, N.F.et al. Modelos para estimar a área foliar de abóbora por meio de medidas lineares. Revista Ceres, Viçosa, v.45, n.259, p.287-291, maio-jun. 1998

SPIEGEL, M. R. Estatística. 3. ed. São Paulo: Pearson Education do Brasil, 1994.

VILHORDO, B. W. et al. Hábito de crescimento em feijão (Phaseolus vulgaris L.). Agronomia Sulriograndense, Porto Alegre, v. 16, n. 1, p.79-98, 1980. 